\title{
An Analysis of the Feasibility and Path of the Integration of "Curriculum Ideological and Political Education" Concepts and College Martial Arts Subjects in the Background of the New Era
}

\author{
Yongzhuang Zhang \\ Taishan University, Tai'an 271000, Shandong, China \\ Email:1225093163@qq.com
}

\begin{abstract}
With the development of my country's big data, cloud computing and other information technologies, college curriculum ideological and political education is accelerating the innovation and development, and the promotion of the integration and synergy of curriculum ideological and political education and specific disciplines is also the focus of current higher education. Based on the particularity of martial arts courses, martial arts culture plays an important role in guiding and regulating the development of courses. Among college physical education courses, martial arts courses are also the closest ideological and political courses. Based on this, this article uses literature method, interview method and other research methods to explore the new era background, feasibility and path of the integration of ideological and political elements and college martial arts discipline literacy. It is hoped that based on the above analysis, we will build a new era of college martial arts. Disciplinary development, comprehensive implementation of the university's goal of "Leading Morality and Cultivating People", and providing suggestions and suggestions for collaborative education.

Keywords: curriculum ideological and political education, martial arts discipline, integration, path
\end{abstract}

\section{Introduction}

Under the background of the new era of comprehensively deepening the reform of curriculum ideological and political education, curriculum ideological and political education is a revolution in the development of my country's curriculum construction in the new era. It is a Chinese vision and Chinese discourse based on my country's local education practice to promote curriculum reform ${ }^{[1]}$. In the "Opinions of the Ministry of Education on Comprehensively Deepening Curriculum Reform and Implementing the Fundamental Task of Lide Shuren", the basic goal of Li de Shu ren as the curriculum ideological and political education teaching concept is further explained, and various disciplines are integrated with ideological and political education. Giving full play to the advantages of collaborative education of various disciplines seems to be the general trend of higher discipline research. At the same time, as a traditional discipline integrating ideology, morality and spirit, the discipline of martial arts complements the pursuit of "curriculum ideological and political education" to a certain extent. The integration of ideological and political elements through college martial arts courses can not only deepen students' understanding of martial arts spirit, but also achieve the goal of discipline and morality. However, how compatible is the curriculum ideological and political education with the ideology of the university martial arts discipline? Whether the integrated development can more effectively interpret the ontological significance of martial arts teaching, this requires not only the rationalization of the ideological and political concepts of the college martial arts teachers in the curriculum, but also the effective improvement of the collaborative education of the college martial arts curriculum under the curriculum ideological and political education concepts. Effect. This article hopes to use the above-mentioned issues to draw insights and arouse the full attention of experts and scholars to the academic literacy of martial arts in colleges and universities.

\section{The new era background of the integration of ideological and political elements and martial arts disciplines in colleges and universities}

\subsection{Informatization of education, accelerating the development of education modernization, is a} new environment for the teaching of martial arts in colleges and universities

Educational informatization is essentially the use of modern educational methods to cultivate innovative talents that adapt to the new era. In other words, the level of informatization of education depends on the level of informatization of school teachers, which in turn affects the development effect of the subject. Since the 19th National Congress of the Communist Party of China emphasized that "building an educational power is the basic project for the great rejuvenation of 
the Chinese nation, and the process of educational modernization must be accelerated", informatization teaching has become a core element of higher education teaching, and it will definitely contribute to the new era of university disciplines. Teaching content and models, methods and methods have produced profound changes and improvements. As the development of martial arts disciplines in colleges and universities in the new era, we should not follow the trend and blindly deny the past martial arts teaching models and methods. We should improve on the basis of integrating ideological and political elements. Thinking from the perspective of traditional teaching is a major problem that needs to be solved urgently. On the one hand, the teaching situation is improved. For example, the "broadcast gymnastics" martial arts teaching class in the past has restricted the intuition and creative thinking ability of martial arts teachers and students to a large extent in terms of time and space. On the contrary, the curriculum ideological and political education pursuit is a teaching mode that integrates subject teaching and modern educational media forms, which expands the learning time and space and promotes the improvement of physical quality, while enabling students to experience the power and effects brought by political thought and spiritual belief; secondly It is the promotion of the role of teachers and the status of students. The "instruction" and "inculcation" martial arts teaching under the influence of traditional inertial thinking matches students who passively accept knowledge and skills, ignoring the implicit education of spiritual thinking. This makes the entire martial arts teaching and learning process a hidden burden. Therefore, the integration of martial arts curriculum and modern multi-functional information technology into classroom teaching allows students to experience the offensive and defensive connotation and cultural spirit of technical movements from a multi-dimensional perspective, and promotes students to be passive in physical learning into an integrated ideology and technology. Beneficiaries.

\subsection{Student and subject literacy is the basic driving force to promote the development of school martial arts subject}

The proposal of student and subject literacy is an important crystallization of our country's basic education moving from "knowledge-based" to "core literacy", marking that teachers should shift from "knowledge-centered" subject teaching to "core literacy" as the core subject education. ${ }^{[2]}$ On the contrary, teachers are an important factor that affects the implementation of students' core literacy, and they play an important role in the development of students' core literacy. ${ }^{[3]}$ First of all, in the process of the in-depth advancement of student core literacy with higher education in the new era, school teachers have gradually integrated into the self-development experience of core literacy. The two are a process of mutual promotion, mutual influence and integration. Secondly, the construction of martial arts disciplines in colleges and universities based on martial arts teaching materials as the carrier of knowledge should always be based on the development requirements and goals of students' life-long growth and social adaptation. Under the current general trend of knowledge integration, college martial arts subject literacy has always been the main shortcoming, and the reform of martial arts subject teaching from "single focus" to "double cultural skills" should also be an important step in cultivating subject literacy in college martial arts. Therefore, this article believes that mastering systematic theoretical knowledge and skills of martial arts disciplines, establishing a new era of school martial arts discipline beliefs, and attaching importance to cultivating students' disciplinary thinking ability are not only the internal driving force to conform to the curriculum ideological and political education renewal of educational concepts, but also the foundation and realization of discipline construction. The fundamental guarantee of "Lide Cultivating People".

\subsection{The integration of traditional martial arts culture with the ideological and political education concepts of the new era is the spiritual pillar for the existence and development of martial arts disciplines}

Martial arts culture, as an important spiritual force for all ethnic groups in our country from ancient times to the present, contains the profound spiritual wealth of the Chinese nation. However, as the trend of cultural globalization continues to deepen, many foreign and inferior cultures in the West have severely subverted people's attitudes at home and abroad. The understanding of the cultural value structure and concepts of the excellent traditional Chinese martial arts. As the inheritance of martial arts education in colleges and universities in the new era, we should always bear in mind that General Secretary $\mathrm{Xi}$ said at the literary work talks: "Traditional Chinese culture is by no means a simple blind xenophobia. The rules, open up yourselves". Therefore, the first step is to move from the ignorance of the emptiness to the self-confidence of the solid culture, that is, to get rid of all self-defeating mentality and deeply grasp the lifeline of martial arts culture. Secondly, with ideological and political education as the main line, the change from blindly from the outside to persisting in the local area, that is, abandoning the cultural concept of vassal, deeply digging and elucidating the spiritual connotation of martial arts culture, so that the integration of traditional culture and ideological and political concepts in our country has become The 
spiritual pillar for the development of martial arts disciplines in colleges and universities.

\section{The feasibility analysis of the fusion of ideological and political elements and college martial arts subject literacy}

\subsection{Macro perspective: requirements for the cultivation of national political feelings and thoughts}

As early as at the National Ideological and Political Work Conference, General Secretary Xi Jinping has repeatedly emphasized that "the realization of the integration of ideological and political and curriculum education must run through the entire educational process." So far, the integration of ideological and political education with various disciplines has created a new situation in my country's higher education. As the so-called glimpse of the so-called, you can see the whole thing. As a traditional discipline of college physical education, the discipline of martial arts, in addition to pursuing the so-called spirit of martial arts, contains more political thoughts on state governance and governance. Obviously, it is in the curriculum ideological and political education. Under the guidance of the concept, the further enrichment of the political thoughts at the national level contained in the martial arts discipline is even more icing on the cake. Let students experience the dynamics of each move and the transformation between internal and external in the martial arts class, and further comprehend the governance thought behind it, and let the ideological and political work run through the entire teaching process of martial arts in colleges and universities, which will improve the spirit of martial arts and shape the quality of sports.Cultivating patriotic political thoughts is of great significance.

\subsection{Middle perspective: the value orientation of ideological and political education and the origin of martial arts thought complement each other}

From the perspective of ontology, martial arts, as a behavior mode that focuses on self-cultivation, integrates ancient Confucianism, Taoism, Buddhism, Mohism, Yin and Yang doctrine and other cultural thoughts in one body. "Self-cultivation, Qi family, rule of the country, peace of the world" Confucianism The martial ethics of "respecting teachers, filial piety and justice, helping the poor and helping the poor, and eliminating violence and peace" has existed in ancient and modern times. It is similar to the ideals of patriotism, moralism, and discipline pursued by ideological and political pursuits. However, for a long time, the awkward situation of martial arts courses that "mother-in-law can't afford, husband-in-law doesn't love" is inseparable from the teaching of martial arts that focuses on techniques, but weakens the teaching of ideological and political elements. Faith, reason, filial piety and other ideological concepts have been put aside; on the other hand, the curriculum ideological and political education system with a coordinated system of ideological and political, time-sharing, and subject and professional integration, with the goal of establishing morality and cultivating people, has obviously become the education of our country today. Guiding ideology. Therefore, from an educational point of view, martial arts disciplines in colleges and universities should be based on morality and cultivating people, based on the principle of "not asking everyone to learn skills, but asking everyone to learn thoughts", with ideological and political teaching as the first priority, and fully tap the source of martial arts moral education. The joint force of educating people in martial arts disciplines will be more effectively used, and the foundation of educating people in martial arts courses will be released.

\subsection{Micro perspective: the common appeal of students' all-round development}

The ideological value system possessed by college students is far from being able to support the diversified development needs of individuals. However, in order to better integrate the teaching concepts of curriculum ideological and political education into the teaching of martial arts in colleges and universities, it must be based on the development of students, and in accordance with the dynamic development of students' thoughts, it is necessary to further strengthen students' thinking and curriculum thinking. The touch of political ideals, active awareness, excavation, and integration of the broad and profound ideas contained in the martial arts discipline itself, so that it gradually builds its own ideological value system. ${ }^{[4]}$ This is not only one of the educating values of martial arts teaching since ancient times, but also an important task for the ideological and political pursuit of the curriculum, and it is also an important foundation for students to develop themselves in an allround way.

\section{An analysis of the path to fusion of ideological and political elements and college martial arts subject quality}

\subsection{Promote the development of thinking with cultural origin}

My country's martial arts culture has a long history, and its cultural connotation is a complex collection of factors and 
characteristics of a nation's economy, culture, ethics, and social organization forms. The martial arts concept of martial arts contains many philosophies such as "ruling by doing nothing, uniting nature and man". Thought. As the martial arts spirit that carries the profound national cultural heritage, it has far-reaching significance for cultivating and promoting the national spirit of self-improvement in the new era. In order to better integrate ideological and political elements in college martial arts courses, and to implement the essence of its morality and cultivating people, it is necessary to trace the roots and explore the roots of martial arts, take the development of martial arts culture as the context, and take the spirit, martial ethics, and patriotism as the core. The purpose is to integrate the current world structure and political environment with the spiritual thought and connotation of traditional martial arts, and then arouse the resonance of students and the collision of students' thinking. Focusing on political ideological nodes through historical issues, gradually looking at the development level of national strategy, and developing college students' patriotic feelings of national governance.

\subsection{Talk about technological innovation by thinking development}

Nowadays, the teaching of martial arts classes in colleges and universities is oriented by single technique teaching, and the phenomenon of focusing on martial arts and neglecting literature has become more and more intense. The reason is that students' long-standing technical learning thinking is not conducive to matching with modern information technology, and "single-form development. The awkward situation of "subtle radiation range". However, new martial arts education carriers and teaching technologies such as multimedia display platforms, VR technology action simulations, information feedback collection platforms, and big data research centers are essential to the diversification of students' thinking innovation and development, so blindly emphasize the learning thinking of body movements. It is also difficult to integrate the elements of ideological and political education more deeply. Therefore, focusing on the knowledge of martial arts culture itself, we should grasp the development of thinking, innovate the ideological and political education discourse method of martial arts courses, develop and use intelligent application software that promotes the exchange of ideas and emotional interaction, and systematically build "school media groups" such as WeChat APP and Weibo. The formation of various martial artsrelated subscription accounts, the matrix effect of the linkage of service accounts, etc., can more easily match the curriculum ideological and political education, and improve the height of technological innovation.

\subsection{Talking about ideological and political spirit with technological innovation}

In the past, the core content of martial arts classes was the teaching of technical movements. It was obvious that there was nothing wrong with the skills of kicking, hitting, throwing, and taking. The inertial thinking of "cultural and ideological education" has never been able to lose the vitality of the development of martial arts classrooms in colleges and universities, making the mainstay of the new era "knowing martial arts rather than loving martial arts" for martial arts culture, which has deviated from the teaching and development of martial arts in colleges and universities. Meaning and direction. From the perspective of psychology, the single-oriented teaching has subtly influenced the continuous development of information technology of students' emotions and attitudes towards martial arts classrooms and even teachers. Nowadays, with the continuous update of integrated platform technology such as online data tracking and collection, big data analysis, and visualization of college students' thought dynamics, how can college martial arts teachers make mainstream values based on technological innovation and the feelings of martial arts educated groups The combination of resonance and martial arts cultural belonging is the first priority of martial arts teaching. Therefore, this article believes that under the guidance of the ideological and political values of colleges and universities, with the help of media technology and the interactive participation of the public, we should build a thinking space that integrates the students themselves with politics, education, economy and other aspects, so as to enable students to understand martial arts culture. The reconstruction of social identity plays a positive role.

\section{Concluding remarks}

In the new era, under the guidance of the trend of curriculum integration of ideological and political education, the ideological and political concept of university martial arts discipline integration curriculum will undoubtedly add luster to university martial arts education. Its rationalization is injected into the professional development of college martial arts teachers and the cultivation of core literacy of disciplines. The "promoting agent" makes it play an important role in promoting the return of the value standard of martial arts education in colleges and universities and the humanized development of the goals and methods of college education by making up for the loopholes in the lack of humanistic spirit of martial arts teachers. From a national perspective, this is a specific practice to implement the policy of "Literally cultivating people"; from the subject itself, under the guidance of a series of new ideological and political concepts, a major transformation and overall improvement of the martial arts discipline in colleges and universities from quantity to quality will be realized. The 
fundamental orientation of martial arts discipline literacy.

\section{References}

[1] Nie Yingping, Fu Anzhou. Curriculum Ideology: A New Perspective of University General Education Reform[J]. University Education Science, 2018, (05): 38-43.

[2] Xu Xingliang. What core nurtures should teachers have[DB/OL]. Available from: http://www.jyb.cn/opinion/pgy$\mathrm{pl} / 201611 / \mathrm{t} 20161117 . \mathrm{html}$

[3] Yu Wensen. The teaching significance of core literacy and its cultivation [J]. Education Today, 2016, (3): 11-14.

[4] Ma Liang, Gu Xiaoying, Li Wei. The practice and thinking of professional teachers' development of curriculum ideological and political education construction from the perspective of collaborative education[J]. Heilongjiang Higher Education Research, 2019, 37(01): 125-128. 